DOI: http://dx.doi.org/10.5007/1980-3532.2015n14p101

\title{
Elementos para se pensar sobre a didática da Sociologia no ensino médio
}

\author{
Elements to think about the didatics of sociology in the secondary \\ education
}

José Aderivaldo Silva da Nóbrega

Doutorando em Ciências Sociais (UFCG)

Professor de sociologia (SEE/Paraíba)

aderivaldocg@gmail.com

\begin{abstract}
Resumo: Já estamos próximos de uma década de retorno da Sociologia aos currículos escolares e o debate acadêmico sobre este fato tem avançado, sobretudo, no que se refere à questão curricular e, mais especificamente, na conversão da produção científica da Sociologia em conteúdos escolares. No presente artigo chamamos a atenção para a necessidade de se intensificar o debate sobre a didática do ensino de Sociologia porque, se por um lado, os objetos de estudo da nossa ciência justificam a sua entrada no ensino médio, por outro, a sua permanência e a sua efetividade estão relacionadas à qualidade do ensino e aos resultados, em termos de aprendizagem, que o nosso trabalho deve apresentar. No texto que segue propomos um debate sobre quais seriam os aspectos pedagógicos, teóricos e metodológicos que estariam em jogo na definição da didática do ensino de Sociologia.
\end{abstract}

Palavras chave: Sociologia. Educação. Didática. Prática de Ensino. Ensino Médio.

\begin{abstract}
We're close to completing a one decade of the return of sociology to the school curriculum and the academic debate about this fact has advanced, particularly as regards the curriculum issue and, more specifically, in the conversion of sociology of scientific production in school curriculum. In this article we draw attention to the need to intensify the debate on the didactics of sociology, because, on the one hand, the objects of study of our science justifies its entry into the secondary education, on the other, its permanence and its effectiveness is related to the quality of teaching and the results in terms of learning, that our work should provide. In what follows we propose a debate on what would be the pedagogical, theoretical and methodological aspects that were at stake in the definition of the didactics of the sociology teaching.
\end{abstract}

Key Words: Sociology. Education. Didactics. Practice of teaching. High school

Originais recebidos em: 20/02/2016

Aceito para publicação em: 06/07/2016

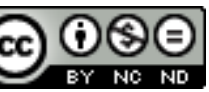

Este trabalho está licenciado sob uma Licença Creative Commons Atribuição-Uso NãoComercial-Vedada a criação de obras derivadas 3.0 Unported License. 


\section{Introdução}

Em 2018 chegaremos aos dez anos de sanção da lei 11.684 que tornou obrigatório o ensino de Sociologia na educação básica - especificamente nas três séries do ensino médio. As implicações, certamente, foram diversas incluindo não só a reformulação curricular, mas um alargamento do campo de pesquisa que, como se percebe no estudo Handfas e Maiçara (2014), tem apresentado temáticas muito variadas que incluem não só a história da disciplina nos currículos escolares como também o próprio currículo, as perspectivas teóricas que informam os conteúdos da disciplina e a percepção de professores e alunos quanto ao ensino desta matéria (HANDFAS e MAIÇARA, 2014, p.52-53).

O que nos preocupa é saber se o estudo de uma técnica de ensino isolada (etnografia em sala, vídeo ou música em sala etc.) ou o relato de qualquer outra atividade sem conexão com todo o contexto que envolve o planejamento e a realização do ensino pode nos informar, de fato, sobre uma prática de ensino de Sociologia e se tal abordagem pode esclarecer sobre o que seria a didática do ensino de Sociologia. Em face desta preocupação temos o objetivo, neste artigo, de discutir sobre o que seria a didática do ensino de Sociologia e sobre quais seriam os aspectos pedagógicos, teóricos e metodológicos que estariam em jogo na definição da prática de ensino.

Dividimos este artigo em várias sessões que apresentam os aspectos que, para nós, seriam muito relevantes para se criar uma compreensão mais complexa acerca da relação entre didática e ensino de Sociologia ou mesmo do que seria a didática do ensino de Sociologia.

\section{Que didática?}

Nesta primeira seção esboçamos um conceito de didática para esclarecer o que pensamos quando nos referimos a este termo para, em seguida, falarmos das preocupações sobre a didática no ensino de Sociologia.

A depender de onde colocamos a nossa lente podemos estar visualizando um campo de estudo ou então um processo que é posto em movimento quando o professor planeja e inicia a sua aula. Se trata, portanto, de um conceito polissêmico. Essa polissemia, como podemos depreender do estudo de Pimenta et al (2013), está 
relacionada aos contextos sociais e históricos. Dependendo deles a didática poderia "ser considerada como a ciência do ensino, a arte do ensino, uma teoria da instrução, uma teoria da formação ou mesmo uma tecnologia para dar suporte metodológico às disciplinas curriculares" (PIMENTA et al, 2013, p.144).

A referência teórica que utilizamos para dar contornos ao conceito de didática é, principalmente, José Carlos Libâneo. Em seu famoso livro intitulado "Didática" ele nos aponta duas possibilidades para pensá-la: ou como campo de estudo da pedagogia ou como meio de trabalho. De acordo com o próprio autor,

\begin{abstract}
a didática é uma das disciplinas da pedagogia que estuda o processo de ensino através de seus componentes - os conteúdos escolares, o ensino e a aprendizagem - para, com o embasamento numa teoria da educação, formular diretrizes da atividade profissional dos professores. É, ao mesmo tempo, matéria de estudo fundamental dos professores e um meio de trabalho do qual os professores se servem para dirigir a atividade de ensino cujo resultado é aprendizagem dos conteúdos escolares pelos alunos (LIBÂNEO, 2006, p.52).
\end{abstract}

Evidentemente, a nossa preocupação no presente artigo não repousa na maneira como o campo da pedagogia tem produzido teorias gerais a respeito da direção do ensino e da aprendizagem. Não vamos fazer uma cartografia das produções teóricas deste campo de conhecimento. Mas, a partir do que nos ensinou Libâneo (2006), queremos refletir sobre esse "meio de trabalho" que o professor constrói para dirigir a atividade de ensino e mediar a aprendizagem dos alunos.

A definição de didática de Libâneo (2006) não está centrada exclusivamente no ato de ensinar, mas, olhando para este ato, o autor se preocupa com a maneira pela qual o professor faz a mediação entre os conteúdos que precisam ser ensinados e os alunos que precisam aprender. Se trata, portanto, de uma definição que considera concomitantemente o ato de ensinar, o ato de aprender e os atores envolvidos no processo. Libâneo (2006) considera que "o processo didático está centrado na relação fundamental entre o ensino e a aprendizagem orientados para a confrontação ativa do aluno com a matéria sob a mediação do professor" (LIBÂNEO, 2006, p.56).

Seguindo a definição e argumentação deste autor, a didática é constituída: a) pelos conteúdos da matéria; b) pelo ato de ensinar que é quando o professor, a partir dos conteúdos planejados e organizados, faz a mediação entre a matéria e o aluno e c) pela ação de aprender, que é quando o aluno assimila de forma consciente e de maneira ativa as matérias apresentadas e, a partir delas, desenvolve habilidades e capacidades. Libâneo (2006) faz sempre questão de enfatizar a participação ativa do aluno no 
processo de aprendizagem. Sua proposição é a de que a passividade do aluno não o faz refletir acerca daquilo que lhe é apresentado como conteúdo e essa falta de reflexão implica negativamente a aprendizagem. Orientados pelo professor, os alunos precisam dispor dos meios para desenvolver suas capacidades e habilidades intelectuais de modo que "dominem métodos de estudo e de trabalho intelectual visando sua autonomia no processo de aprendizagem e independência de pensamento" (LIBÂNEO, 2006, p.71). O professor precisa encontrar os recursos necessários para estimular a disposição dos alunos para o estudo e para aquisição dos conhecimentos. $\mathrm{O}$ autor é consciente de que essa tarefa de ensinar didaticamente não é fácil e nem se realiza de forma automática:

Não é uma atividade que se desenvolve automaticamente, restrita ao que se passa no interior da escola, uma vez que expressa finalidades e exigências da prática social, ao mesmo tempo em que se subordina a condições concretas postas pela mesma prática social que favorecem ou dificultam atingir objetivos. Entender, pois, o processo didático como totalidade abrangente implica vincular conteúdos, ensino e aprendizagem a objetivos sóciopolíticos e pedagógicos e analisar o conjunto de condições concretas que rodeiam cada situação didática (LIBÂNEO, 2006, p.56)

Poderíamos pensar que o professor que trabalha de forma didática possui o domínio dos conteúdos da matéria que leciona, tem a habilidade de relacioná-los com os objetivos pedagógicos e sócio-políticos e, por conseguinte, relaciona-os com as metodologias e técnicas mais adequadas para sua apresentação de modo que os alunos consigam aprender. Evidentemente, cabe ao professor ter um olhar crítico sobre quais são os interesses que estão por trás dos objetivos que são propostos no seu programa de ensino e quais as consequências de sua execução.

É importante salientar, em concordância com Contreras (1990), que a didática não é um elemento normativo que engessa o processo de ensino. Ela é parte "da trama das ações políticas, administrativas, econômicas e culturais contextualizadas que incidem na práxis do ensino" (CONTRERAS, 1990, p.17).

Neste nosso primeiro movimento, podemos ensaiar uma síntese e afirmar que a didática é uma prática social na qual os professores mobilizam os conteúdos de determinado campo do conhecimento, organizados e dispostos na forma de matéria escolar, e apresentam esse conteúdo aos alunos utilizando-se, para tanto, de várias técnicas de abordagem a fim de que eles consigam aprender.

Na próxima seção enfrentaremos o seguinte questionamento: que nexos podem se constituir entre a didática e a Sociologia enquanto disciplina do ensino médio? 


\section{Didática e ensino de Sociologia}

A práxis do professor de Sociologia que leva em conta, dentre vários aspectos, a didática, visa a aprendizagem dos alunos a partir do ensino realizado de acordo com a especificidade do conhecimento sociológico transformado em conhecimento escolar considerando as metodologias de abordagem condizentes com esse tipo de conhecimento bem como os contextos sócio-político-culturais e pedagógicos que instauram as exigências educacionais e de ensino. A construção dos nexos entre didática e a Sociologia ocorre a partir do esclarecimento que tem o professor sobre "os objetivos da educação e da instrução, os conteúdos, o ensino, a aprendizagem, os métodos e a avaliação" (LIBÂNEO, 2006, p.57).

\section{Os objetivos do ensino médio em geral e da Sociologia em particular}

Uma das principais referências para a definição dos objetivos do ensino médio é, sem dúvida, a Lei 9394/1996 que estabelece as diretrizes da educação nacional. Nela são apresentadas as finalidades do ensino médio dentre as quais destacamos: a preparação do jovem para o mundo do trabalho e para o exercício da cidadania; a oferta de uma formação ética e que dê condições para o desenvolvimento intelectual e do pensamento crítico (BRASIL, 1996, p. 1). Tais finalidades são desdobradas em outros documentos oficiais como os pareceres do Conselho Nacional de Educação (CNE) e outras publicações vindas do Ministério da Educação (MEC).

Em 2011 o Conselho Nacional de Educação aprovou o parecer 05/2011 que legitimou as novas Diretrizes Curriculares Nacionais para o Ensino Médio. Neste documento se afirma que o ensino médio tem o objetivo de oferecer aos jovens uma "formação humana integral evitando a orientação limitada de preparação para o vestibular” (BRASIL, 2013a, p.155). Argumenta-se que essa formação integral, que visa superar o caráter propedêutico do ensino médio, se sustenta em quatro pilares que são os seguintes: trabalho, ciência, tecnologia e cultura.

O trabalho é apresentado no referido documento como uma categoria central para entender as transformações na sociedade e suas várias formas de organização; é também uma categoria importante para compreender a grandeza das criações humanas e, ao mesmo tempo, identificar as contradições das relações humanas como a 
concentração de renda, a exploração do trabalhador e as formas de trabalho degradantes. O trabalho como princípio educativo refere-se à compreensão de que nós deixamos a nossa marca no mundo através das transformações que nele engendramos através do trabalho. Somos sujeitos da história e devemos produzi-la através da nossa iniciativa e da nossa criação materializada por meio do trabalho.

O parecer 05/2011 do CNE conceitua a ciência como uma forma sistematizada de conhecimento produzido socialmente ao longo da história resultando da busca da compreensão e transformação da natureza e da sociedade (BRASIL, 2013a, p.161).

O pilar da ciência visa colocar o aluno em contato com a linguagem própria da ciência que se expressa através de seus conceitos e teorias. Esses conhecimentos são apropriados e transformados em tecnologia, que é o terceiro pilar proposto pelo parecer. Nos termos do parecer a tecnologia é a mediação dos conhecimentos científicos e a produção, isto é, a intervenção na realidade empírica.

O último pilar proposto para essa "formação integral" é a cultura. Segundo o referido parecer a cultura é o conjunto de representações e comportamentos que informam um modo de viver de determinado grupo. Visa, portanto, favorecer uma compreensão da diversidade e, ao mesmo tempo, dos mecanismos pelos quais os povos afirmam sua identidade e sua especificidade.

O objetivo de oferecer uma formação humana integral no ensino médio, para a Sociologia, não constitui, em princípio, nenhum problema. Nossa disciplina possui muitos campos de estudo focados em cada uma destas dimensões (trabalho, ciência, cultura e tecnologia) e são muitas as teorias, os conceitos e os autores ${ }^{1}$ que podem servir de referência para abordagem de cada um destes quatro pilares. Além disso, a possibilidade de interdisciplinaridade da Sociologia facilita um diálogo entre os professores das outras matérias no sentido de formular planos de ensino, planos de intervenção no cotidiano escolar entre outras ações que tirem do papel estes pilares. De toda sorte, nosso argumento é que o conhecimento sociológico possui um vasto repertório teórico, temático e conceitual para subsidiar um programa de estudos que vise a formação integral dos indivíduos. Mas, é preciso desdobrar esse objetivo geral do ensino médio, a formação integral, em objetivos específicos da Sociologia.

\footnotetext{
${ }^{1}$ Qualquer menção que pudéssemos fazer aos diversos autores dentro dos vários campos de estudo (trabalho, cultura, ciência e tecnologia) seria demasiado extenso e nos levaria para longe do objeto mais central da nossa reflexão.
} 
A definição dos objetivos de nossa matéria para o ensino médio tem sido tema de debates em congressos e encontros sobre ensino de Sociologia. Aos poucos, começam a ser divulgados os resultados de pesquisas sobre esta temática. Um exemplo destes estudos é o das pesquisadoras Julia Polessa Maiçara, Gabriela Montez e Beatriz Gesteira que publicaram recentemente em uma coletânea (HANDFAS, MAIÇARA e FRAGA, 2015) os resultados de uma pesquisa sobre a percepção dos objetivos da Sociologia no ensino médio pelos professores. Este estudo, desenvolvido no Rio de Janeiro entre 2010 e 2012, constatou, a partir de 24 entrevistas realizadas, que a maioria dos professores entendem que o objetivo da Soci ologia é ser

uma ferramenta para o aluno entender a sociedade, estimulando a capacidade crítica, especialmente a capacidade de desnaturalizar fenômenos sociais contrapondo o pensamento sociológico ao senso comum e contribuindo para uma formação cidadã (MAIÇARA, MONTEZ e GESTEIRA, 2015, p.102).

Com a preocupação de não tornar as Orientações Curriculares Nacionais (OCN's) uma guilhotina a cortar as possibilidades do ensino de Sociologia, seus formuladores acabaram definindo os objetivos desta matéria a partir do desdobramento de dois princípios epistemológicos fundamentais: a desnaturalização e o estranhamento. Quanto à noção de desnaturalização as OCN's afirmam:

Há uma tendência sempre recorrente a se explicarem as relações sociais, as
instituições, os modos de vida, as ações humanas, coletivas ou individuais, a
estrutura social, a organização política, etc. com argumentos naturalizadores
Primeiro, perde-se de vista a historicidade desses fenômenos, isto é, que nem
sempre foram assim; segundo, que certas mudanças ou continuidades
históricas decorrem de decisões, e essas, de interesses, ou seja, de razões
objetivas e humanas, não sendo fruto de tendências naturais. (BRASIL, 2006,
p.106)

A desnaturalização consiste em perceber que determinados fatos, por serem muito recorrentes e por estarem muito próximos de nós parecem ser naturais, mas, na verdade, têm muito a ver com as consequências das nossas decisões e/ou da nossa intervenção no mundo.

Em relação ao estranhamento as OCN's nos ajudam a questionar todo argumento que coloque os fatos e acontecimentos como normais e, portanto, fechados a uma explicação mais aprofundada. Utilizando a obra "O suicídio" de Durkheim, os formuladores das OCN's mostram como este estudo permitiu explicar o suicídio de uma forma diferente daquela à qual as pessoas estavam acostumadas a ouvir e a aceitar passivamente. 
Estranhar o fenômeno "suicídio" significa, então, tomá-lo não como um fato corriqueiro, perdido nas páginas policiais dos jornais ou boletins de ocorrência de delegacias, e sim como um objeto de estudo da Sociologia; e procurar as causas externas ao indivíduo, mas que têm decisiva influência sobre esse, constitui um fenômeno social, com regularidade, periodicidade e, nos limites de uma teoria sociológica, uma função específica em relação ao todo social (BRASIL, 2006, p.108)

As pessoas tendem a atribuir o suicídio a um fenômeno meramente psicológico e, nesse automatismo, se torna difícil relacioná-lo à fatores que não sejam distúrbios psicológicos ou forças sobrenaturais ou espirituais negativas etc. Nos termos propostos por Moraes e Guimarães (2010): “estranhar, portanto, é espantar-se, é não achar normal, não se conformar, ter uma sensação de insatisfação perante fatos novos ou do desconhecimento de situações e de explicações que não se conhecia" (MORAES e GUIMARÃES, 2010, p.46)

Por que o estranhamento e a desnaturalização aparecem como pressupostos da Sociologia? Esta é uma atitude cognitiva que os intelectuais reconhecidos como os nossos clássicos já desenvolviam e que acabou estruturando nosso campo do conhecimento. Assim, por exemplo, ao pensar sobre a emergência de uma sociedade em que as vinculações sociais se tornaram complexas dando origem à "solidariedade orgânica" (DURKHEIM, 2004); ao pensar em uma nova "racionalidade" que orienta o sentido da ação social (WEBER, 2004), ou mesmo, ao pensar uma certa formação social marcada pela existência e conflito entre classes (MARX, 2013), Durkheim, Weber e Marx estavam colocando as grandes questões de seu tempo sob perspectivas muito diferentes e distanciadas das percepções do senso comum da época. Desde as origens do pensamento sociológico nota-se a especificidade de um saber que se constitui a partir dos fatos do cotidiano, porém, que não se limita à mera constatação e descrição, mas que, além disso, busca explicar o que está nas entrelinhas destes fatos e de que maneira eles têm implicação na vida social. Falando a partir de autores contemporâneos, especificamente Giddens (2001), diríamos que a "Sociologia estabelece uma relação muito mais direta com as questões que dizem respeito à nossa vida cotidiana" (GIDDENS, 2001, p.14). Ainda segundo o mesmo autor, o conhecimento sociológico "é parasítico dos conceitos dos leigos agentes", mas é preciso lembrar que o conhecimento tem a força de influenciar a reelaboração das explicações que damos ao que se passa no mundo social. "O conhecimento sociológico espirala dentro e fora do universo da vida social, reconstituindo tanto este universo, como a si mesmo, como uma parte integral deste processo" (GIDDENS, 1991, p.24). 
Essa característica do conhecimento sociológico implica muito sobre a forma como definimos os objetivos de nossa matéria escolar. Sintetizando aquilo que temos lido e ouvido de professores o ensino de Sociologia se encaminha para três grandes objetivos que passaremos a explorar.

O primeiro é compreender o mundo social no qual o aluno está envolvido. Quais são as coletividades nas quais está inserido, de onde vem e como são formuladas as regras que orientam e limitam sua maneira de ser e de se comportar e que problemas surgem no convívio cotidiano. Estas são questões muito importantes que ajudam os alunos a perceberem, a partir de seu próprio contexto, a complexidade do mundo social. De um modo diferente diz Mannheim (1962):

Cumpre que se torne sensível, pelo estudo da Sociologia, à estrutura da ordem social em que se vive, ao impacto óbvio ou disfarçado dos grupos sociais e à relação entre as pessoas e à ordem social em que elas se acham colocadas (MANNHEIM, 1962, p.176).

Ainda dentro deste primeiro grande objetivo, diríamos que é importante perceber que certos acontecimentos em nossa vida, por mais que pareçam meramente individuais, podem ter relação com o que é coletivo conforme explica Mills (1965):

Quando uma sociedade se industrializa, o camponês se transforma em
trabalhador; o senhor feudal desaparece ou passa a ser homem de negócios;
quando as classes ascendem ou caem, o homem tem emprego ou fica
desempregado (...); quando há guerras, o corretor de seguros se transforma no
lançador de foguetes; o caixeiro de loja, em homem do radar; a mulher vive
só, a criança cresce sem pai. A vida do indivíduo e a história da sociedade
não podem ser compreendidas sem compreendermos essas alternativas.
(MILLS, 1965, p.9-10)

Assim, na chave do estranhamento e da desnaturalização, poderíamos dizer que esta compreensão do mundo social é, antes, histórica porque as nossas relações mudam, assim como mudam as instituições, as normas etc. Elas se diferenciam também de acordo com o conjunto de relações que se estabelecem em cada sociedade.

O segundo objetivo da Sociologia no ensino médio é possibilitar a percepção dos diversos discursos que justificam e explicam o mundo social. As religiões, por exemplo, são uma importante fonte de explicação e de justificação do mundo em que vivemos. E nós encontraremos na sala de aula muitos alunos, participantes de igrejas, que em razão de princípios religiosos poderão ter dificuldades de discutir questões de gênero e a própria diversidade de crenças religiosas exatamente pela força que a vivência de determinada doutrina exerce sobre a subjetividade e o comportamento. Não está nos nossos objetivos anular a importância da religião para o entendimento da vida social 
utilizando, para tanto, conceitos sociológicos. Lembremos que um dos trabalhos mais cruciais do Weber (2004) abordava, justamente, como uma ética religiosa guarda afinidades com as características do capitalismo ocidental. Portanto, nosso objetivo é muito mais destacar a especificidade do pensamento sociológico frente a forma religiosa de entender o que se passa no mundo.

Algumas explicações que perpassam o campo da religião e nascem da repetição de ideias que ouvimos no nosso dia a dia a ponto de elas se tornarem aceitas e validadas pelo chamado senso comum. Não paramos, na maioria das vezes, para refletir sobre os fundamentos de certas ideias do senso comum e, por apenas repeti-las acabamos perdendo a capacidade de flagrar as contradições, os preconceitos, a falta de lógica e coerência etc. Daí porque as explicações do senso comum estão mais passíveis de reproduzirem problemas como preconceitos, racismos, intolerância, discriminação, sexismos, xenofobismos e muitos outros tipos de raciocínio e de condutas que precisam ser problematizados.

Se, por um lado, tais elementos problematizáveis que estão contidos no senso comum exigem de nós uma postura de crítica, por outro lado, essa crítica não deve ser tomada como a eliminação do senso comum da sala de aula. Este ponto é polêmico e constitui um ponto do qual discordamos dos muitos discursos que colocam a Sociologia como responsável por fazer com que os alunos eliminem de suas cabeças o senso comum. Reparemos que este tipo de discurso não só propõe um contraste entre as formas de conhecimento (Sociologia acadêmica $\mathrm{x}$ senso comum) como coloca numa chave de destruição de um pelo outro. A relação da Sociologia com o senso comum é muito bem colocada por Moraes e Guimarães (2010):

É contribuição das Ciências Sociais, como a disciplina Sociologia para o nível médio, propiciar aos jovens o exame de situações que fazem parte do seu dia a dia, imbuídos de uma postura crítica e atitude investigativa. É sua tarefa desnaturalizar os fenômenos sociais, mediante o compromisso de examinar a realidade para além de sua aparência imediata, informada pelas regras inconscientes da cultura e do senso comum (MORAES, GUIMARÃES, 2010, p.48)

Sob o nosso ponto de vista, o conhecimento sociológico é luz que se projeta sob as sombras que o senso comum não consegue clarear, ou seja, a Sociologia visa apontar os limites do senso comum em compreender de forma mais complexa, aprofundada e crítica determinadas questões sociais indo além das aparências imediatas. 
O terceiro objetivo da Sociologia no ensino médio tem relação com o mantra "formar o cidadão crítico". Os formuladores das OCN's tiveram bastante razão ao colocarem este como sendo um "clichê" muito falado, mas que não deve ser o fim único da nossa matéria. O senso comum, quando posto diante da palavra cidadania, tende a reconhecer algumas noções correlatas: direito, dever e voto. E, por mais que estas três noções estejam presentes no universo da cidadania, a abordagem da Sociologia requer mais complexidade.

Mota (2005) fez um balanço sobre como os professores justificam a Sociologia no ensino médio e ressalta que, recorrentemente, aparece a ideia dos professores entrevistados pela autora de que a nossa matéria deve esclarecer os nossos direitos e deveres. A autora critica essa simplificação:

$$
\begin{aligned}
& \text { mais do que uma definição jurídica e um "conteúdo" de sala de aula, } \\
& \text { cidadania implica valores e práticas que envolvem o cotidiano das pessoas. } \\
& \text { Esses valores e práticas fundamentam-se e constroem se em uma moralidade, } \\
& \text { cuja natureza é sempre historicamente condicionada (MOTA, 2005, p.97). }
\end{aligned}
$$

A cidadania envolve muito mais do que a definição jurídica de direito e dever. Envolve a reflexão sobre os processos sociais que deram origem aos direitos, deveres e também originaram as formas de participação social e de atuação política. Como será empobrecedor falar, por exemplo, do direito de votar que exercemos no Brasil mencionando apenas o dispositivo constitucional sem considerar as lutas sociais que garantiram a sua existência e sem problematizar a forma como ele é exercido atualmente. Concordamos com Mota (2005) que é um reducionismo fazer do estudo da cidadania um ato arrolar direitos e deveres. "Essa é uma perspectiva reducionista da cidadania como mera condição legal limitada ao nível institucional e formal” (MOTA, 2005, p.97).

Na perspectiva do ato de ensinar, portanto, a cidadania não se apresenta apenas como a descrição de direitos e deveres, mas, para além disto, como o conhecimento crítico dos processos sociais a partir dos quais estes direitos e deveres vão se constituindo e dos papéis desenvolvidos por sujeitos e instituições. O estudo da cidadania não é meramente descritivo, mas deve considerar processos, mudanças e correlações de forças que, no campo das lutas sociais, acabam influenciando a organização social, a composição dos governos, a estruturação do sistema políticopartidário etc. 
Outro ponto de tensão que é levantado por Mota (2005) e que também nos preocupa é a suposição implícita de que aprendemos sobre cidadania na teoria para colocarmos em prática quando concluirmos nossos estudos e não formos mais alunos:

Justificar a Sociologia em virtude da formação para a crítica e para a cidadania pressupõe preparar os jovens para "um depois"; eles precisam aprender certos conteúdos para um dia exercer essas condições. E a escola não faz parte da trama social atual? Nela não se exerce a crítica e a cidadania? Argumentar a importância do conhecimento sociológico segundo aquele horizonte pode negar aos jovens a participação política; protela-se essa possibilidade em vista dos seus "desinteresses, descompromissos, apatias", como frequentemente são caracterizados por professores. (MOTA, 2005, p.99)

É importante frisar que a própria escola é o espaço, por excelência, para se aprender e, ao mesmo tempo, exercitar a cidadania. No discurso corrente dos formadores de professores o processo de ensino tem o aluno como sujeito principal e não mais como expectador de um processo unilateral. $\mathrm{O}$ pressuposto da participação juvenil seja pela pesquisa e pelos projetos pedagógicos guarda, em si, um potencial significativo para tratar da cidadania.

O Laboratório de Ensino, Pesquisa e Extensão de Sociologia, da Universidade Estadual de Londrina publicou, em 2009, um caderno contendo várias experiências ${ }^{2}$ de projetos pedagógicos e algumas que são descritas no caderno são muito relevantes para abordagem da cidadania. Uma delas tem como tema central a organização das eleições do grêmio estudantil. Esta experiência a que aludimos foi descrita por Silva (2009) que deixa muito claro que os professores aproveitaram o caloroso debate a respeito da eleição de grêmio estudantil para a abordar a relação do movimento dos estudantes com a cidadania. $\mathrm{O}$ que é interessante nesta experiência prática é que se trabalhou com a sequência didática o que permitiu, ao longo de alguns encontros com os alunos, refletir sobre as formas como nos mobilizamos para atender as nossas necessidades enquanto grupo; sobre o movimento estudantil e sua forma de luta ao longo da história brasileira; quais as questões reivindicadas e quais as conquistas. Os professores não pararam nisso, mas colocaram o foco na própria escola e nas necessidades dos alunos e, sobretudo, na organização em torno dos seus interesses e na mobilização para o diálogo com professores e a direção da escola. Leituras de caráter mais histórico, músicas, poesias,

2 Para conhecer e baixar, na íntegra, o material basta acessar o link: https://www.google.com.br/url?sa=t\&rct=j\&q=\&esrc=s\&source=web\&cd=1\&ved=0ahUKEwj3jeWNmjKAhVDDJAKHUwSDkYQFggmMAA\&url=http\%3A\%2F\%2Fwww.uel.br\%2Fprojetos\%2Flenpes\%2F pages $\% 2$ Farquivos $\% 2$ FLIVRO $\% 2520$ INTEIRO $\% 2520 \mathrm{em} \% 2520$ PDF\%2520\%2520LENPES\%2520$\% 252002 \% 2520 \mathrm{de} \% 2520 \mathrm{dez}-1$. pdf\&usg=AFQjCNHDR-L8rx2LQ6uX_liGQCoPg3Safw\&cad=rja 
filmes, debates e planejamento dos alunos em torno de questões concretas são destaques desta iniciativa.

A partir deste exemplo temos a possibilidade de ressaltar que formar o cidadão crítico implica não só um compromisso da Sociologia com o futuro dos alunos, mas também com o seu presente e isso nos faz levantar os seguintes questionamentos: Qual é o espaço que o aluno tem para apresentar suas necessidades ao professor e à direção? Como o aluno apresenta essa reivindicação? Por outro lado, quais são as reponsabilidades daquele ambiente social escolar que são exigidas dos alunos? São cumpridas essas exigências? Quais as formas de participação do aluno nas decisões que influenciam a vida escolar no geral? Enfim, como os diversos grupos sociais que vivem nesse sistema chamado escola tornam possível a sua coexistência? O aprendizado sobre cidadania nos parece ser, diante do que expusemos, muito mais resultado de uma prática social cotidianamente vivia na escola do que, propriamente, uma abstração de determinadas noções que foram lidas a partir do livro didático.

Uma concepção de didática que leva em consideração estes três objetivos aos quais aludimos abordará os conteúdos de ensino ressaltando sempre o seu caráter histórico, portanto, sua possibilidade de mudança; abordará a participação humana na produção de determinados fatos problematizando sempre as explicações que tendam a defender determinismos naturais ou sobrenaturais em relação a problemas cuja ação humana tem grande importância; abordará, portanto, a participação humana em sua própria trajetória de sobrevivência o que implicou, ao longo da história, certas estruturas que acabaram condicionando nossas relações sociais.

Nossa didática exige transformar estes pressupostos em conteúdos escolares constantes nos programas de ensino aos quais submeteremos nossos alunos. Eis ai mais um ponto de tensão no debate sobre a didática do ensino da Sociologia.

\section{Os conteúdos da Sociologia no ensino médio}

Se as OCN's não relacionam um conjunto de assuntos a serem ensinados na nossa matéria, não seremos nós em um artigo de espaço limitado que o faremos. Levantaremos apenas alguns pontos que nos ajudarão a pensar na formulação no nosso programa de ensino. É bom termos presente que a Sociologia como matéria escolar do ensino médio sempre é um recorte de um campo muito mais amplo e complexo. A 
formulação do plano de ensino é algo sempre relacionado ao contexto da escola e muito relativo às características do professor e das referências que ele tem sobre o que deveria ser ensinado. Como o professor constrói suas referências? Libâneo (2006) dá alguns indicativos sobre esta questão:

Três fontes que o professor utilizará para selecionar os conteúdos de seu plano de ensino e organizar suas aulas: programação oficial na qual são formulados os conteúdos de cada matéria; a segunda são os próprios conteúdos básicos das ciências transformadas em matérias de ensino; a terceira são as exigências teóricas e práticas colocadas pelas práticas de vida dos alunos tendo em vista o mundo do trabalho e a participação democrática na sociedade (LIBÂNEO, 2006, p.133)

Não existe um programa oficial, no entanto, alguns elementos acabam condicionando a relação oficial dos conteúdos a serem ensinados. O condicionamento mais forte é o Exame Nacional do Ensino Médio (ENEM) que, nos editais dos últimos anos, tem indicado grandes temas muito importantes entre os quais citamos: diversidade cultural, conflitos e vida em sociedade; formas de organização social, movimentos sociais, pensamento político e ação do Estado; características e transformações das estruturas produtivas (BRASIL, 2013b; BRASIL, 2014; BRASIL, 2015). Estes temas gerais se desdobram em uma série de conteúdos que remetem a conceitos como: cultura, identidade, grupo étnico, cidadania, desigualdades sociais, instituições, Estado, regimes políticos, trabalho, flexibilidade do trabalho entre outros.

O MEC lançou, em 2010, a coleção explorando o ensino (BRASIL, 2010) que contém 15 volumes com textos sobre temas das várias disciplinas escolares, inclusive a Sociologia. O $15^{\circ}$ volume, que trata da Sociologia, está dividido em duas partes, sendo a primeira dedicada às orientações didáticas ao professor e, a segunda, com 12 textos, dedicada a abordagem dos seguintes temas: juventude; trabalho na sociedade contemporânea; violência; Religião, sistema de crenças, feitiçaria e magia; diferenças e desigualdades sociais; Sociologia, tecnologias de informação e comunicação; cultura e alteridade; família e parentesco; grupos étnicos e etnicidade; democracia, cidadania e justiça; Estado, partido e governo e o Brasil no cenário internacional (tema das relações internacionais e globalização). Os textos não são propriamente para serem lidos pelos alunos, mas, prioritariamente, para serem lidos pelo professor a fim de que ele tenha subsídio para elaborar sua aula.

Entre os colegas professores da Sociologia parece haver convergência de certos conceitos. Para sintetizar este debate faremos referência a duas pesquisas. Maiçara, 
Montinez e Gesteira (2015), já citadas, abordam a percepção dos professores sobre nossa matéria. As autoras relacionaram os temas mais recorrentes entre os professores do Rio de Janeiro foram os seguintes: cidadania, cultura, desigualdade social, mundo do trabalho, clássicos da Sociologia.

Já no estudo de Sousa e Manginelli (2015) sobre o currículo no Estado do Paraná aparecem conceitos como: socialização, cultura e indústria cultural, classe social, direito, política e cidadania, trabalho etc. Se nos aprofundássemos na investigação dos conteúdos propostos em cada Estado veríamos poucas variações dentro de um mesmo campo de conceitos. Estas variações dizem respeito a quais conteúdos, temas ou teorias são abordados na primeira série, quais na segunda e quais na terceira.

O livro didático é outro fator importante na definição do plano de ensino. Em que pese o aumento das opções de livros no mercado editorial e a melhoria da sua qualidade, como investigam e atestam Oliveira e Cigales (2015), é importante frisar que o livro é uma ferramenta a mais que pode contribuir com a elaboração do plano de ensino e com a execução da aula. A prática corrente, entretanto, é de tomar o sumário de um determinado livro didático e distribuí-lo em quatro unidades (ou bimestres como chamamos na Paraíba). Desconsiderando-se a qualidade do texto em si, na hora de escolha do livro valoriza-se bastante a oferta de muitos temas, com fotos, trechos de música, sugestões de questões do ENEM e muitos outros aspectos mais relacionados ao ensino que preparam para o vestibular. Isso pode levar o professor para longe da formação integral dependendo da forma que ele conduz seu trabalho. É claro que isto é um problema que exige de nós vigilância. Não parece razoável atribuir ao sumário de um livro a responsabilidade de definir todo um ano de trabalho.

Sim, o professor tem de ter em vista o livro didático, as orientações curriculares oficiais, o próprio universo de objetos de conhecimento reconhecido pelos praticantes da Sociologia, mas, ele deve ter sempre aberta a possiblidade de mobilizar todas estas referências de acordo com o contexto e a situação da escola em que leciona.

\section{O ensino e as possibilidades metodológicas}

Já parece estar sedimentado no pensamento dos professores de Sociologia o pressuposto metodológico de que o ensino de nossa matéria pode ser organizado segundo três recortes: conceitos, teorias e temas como sugerem as OCN's. 
Ao se tomar um conceito - recorte conceitual -, este tanto faz parte da aplicação de um tema quanto tem uma significação específica de acordo com uma teoria, do contrário os conceitos sociológicos seriam apenas um glossário sem sentido, pelo menos para alunos do ensino médio. Um tema não pode ser tratado sem o recurso a conceitos e a teorias sociológicas senão se banaliza, vira senso comum, conversa de botequim. Do mesmo modo, as teorias são compostas por conceitos e ganham concretude quando aplicadas a um tema ou objeto da Sociologia, mas a teoria a seco só produz, para esses alunos, desinteresse. (BRASIL, 2006, p.117)

Está claro, portanto, que estes três recortes se combinam e a forma como isto ocorre vai depender da situação didática em questão. Em nossa experiência buscamos sempre partir de temas enfatizando, primeiro, como o senso comum os aborda e, então, prosseguimos ressaltando que a Sociologia se preocupou com esse tema e os sociólogos desenvolveram certos conceitos. Não pode ser desconsiderado que estes conceitos são articulados e compõem teorias. Tratar destas questões exige um planejamento muito criterioso a fim de que a discussão não fique nas percepções do senso comum e, portanto, aula se torne semelhante a uma conversa em praça pública no sábado à noite, mas também, não se quer complexificar a abordagem de modo que os alunos se sintam fechados nas cúpulas de sociólogos em seus congressos. Há necessidade de um ponto de equilíbrio entre estes dois polos.

A experiência que temos é que a articulação entre conceito, teoria e tema ocorre da melhor maneira quando adotamos a técnica da sequência didática.

\begin{abstract}
As sequências de atividades de ensino/aprendizagem, ou sequências didáticas, são uma maneira de encadear e articular as diferentes atividades ao longo de uma unidade didática. Assim, pois, poderemos analisar as diferentes formas de intervenção segundo as atividades que se realizam e, principalmente, pelo sentido que adquirem quanto a uma sequência orientada para a realização de determinados objetivos educativos. As sequências podem indicar a função que tem cada uma das atividades na construção do conhecimento ou da aprendizagem de diferentes conteúdos e, portanto, avaliar a pertinência ou não de cada uma delas, a falta de outras ou a ênfase que devemos lhe atribuir (ZABALA, 1998, p.20).
\end{abstract}

Nós, que temos apenas uma aula de 50 minutos por semana, que enfrentamos a dificuldade de usar todos os minutos de maneira produtiva sem deixar de fazer a lista de frequência e mantendo disciplina dos alunos não conseguimos começar e terminar a abordagem de um determinado conceito, tampouco, introduzir minimamente, mas sem distorções, uma teoria em apenas uma aula ${ }^{3}$. Por causa destas questões que a sequência didática surge como uma forma de organizar o processo de ensino-aprendizagem.

\footnotetext{
${ }^{3}$ No Estado da Paraíba os alunos das $1^{\mathrm{a}}, 2^{\mathrm{a}}$ e $3^{\mathrm{a}}$ séries têm uma aula de Sociologia por semana e isso implica um longo espaço de tempo até que o professor reencontre seus alunos para seguir o assunto
} 
As sequências didáticas ${ }^{4}$ permitem que o professor lide com as diversas estratégias de socialização de informações, noções, teorias etc. e, deste modo, pode contemplar as várias formas de aprendizagem (por leitura, pela audição, pelo visual, pelo audiovisual etc.). Assim, o professor pode, numa dada sequência começar por uma exposição, seguida de debate fomentado por uma música, um filme, uma charge ou qualquer outro elemento de ilustração e o processo de aprendizagem sobre determinado conteúdo vai se aprofundando ao longo das aulas. Na verdade, não há limite para a criatividade desde que seja mantido o rigor na enunciação dos conceitos, teorias e, ao mesmo tempo, flexibilidade para participação dos alunos que não devem ser passivos no processo.

É importante que o professor tenha consciência que certas atividades favorecem determinadas habilidades. A atividade de debate, como sugere Bridi, Araújo e Motim (2010), dá a oportunidade ao aluno de "contrapor questões a serem apreciadas de vários pontos de vista, de expor teses centrais, argumentar, fazer inferências, construir hipóteses, confrontar ideias, dialogar, apontar soluções e encaminhamentos" (BRIDI, ARAÚJO E MOTIM, 2010, p.152). Não valerá a pena esta atividade se não houver tempo para prepará-la e para sua completa execução. Além disso, se nas defesas dos alunos, não houver demonstração de certo domínio do vocabulário sociológico ou que, pelo menos se demonstre estranhamento e desnaturalização, o resultado terá sido insatisfatório.

São muitos os fatores que devem ser ponderados na hora de optar por determinada atividade em sala de aula. Consideremos, pois, o tempo disponível da atividade, o acesso aos materiais necessários ao seu desenvolvimento, o tipo de envolvimento da turma e a diversidade de capacidades dos alunos - isso é importante para não sobrecarregar uns enquanto que outros, por não dominarem determinada habilidade acabam não se envolvendo.

trabalhado. As sequências didáticas nos ajudam a fazer com que esta longa demora entre uma aula e outra não prejudique muito a cadência da aprendizagem.

\footnotetext{
${ }^{4}$ Além das indicações de sequencias que já vêm em alguns livros didáticos, o acesso a experiências já realizadas é muito fácil. Para tanto, recomendamos o acesso à plataforma Portal do Professor (http://portaldoprofessor.mec.gov.br); à página da secretaria estadual de educação do Paraná que disponibiliza muitos recursos (http://www.sociologia.seed.pr.gov.br) e ao portal do Banco Internacional de Objetos Educacionais (http://objetoseducacionais2.mec.gov.br). Todos os recursos dispostos nestes sites podem ser baixados e utilizados pelos professores.
} 
O acesso aos recursos tecnológicos, mais precisamente aos que se relacionam ao audiovisual e à informática, causam a ideia de que a aula será muito proveitosa o que pode ser um engano. Basta que o formato de um vídeo não seja compatível com o televisor ou que o som não seja de boa qualidade e o volume baixo para que os 50 minutos produtivos se tornem uma verdadeira guerra entre o professor e a máquina. Além do mais, acaba causando a sensação de que o professor não tem controle da situação e dá margem a reclamações dos alunos, barulho, dispersão etc.

Não esgotamos todas as técnicas que poderíamos utilizar na atividade de ensino, mas, tendo já recomendado, a partir da nossa experiência de sala de aula, determinados portais, cabe-nos sempre lembrar a importância da leitura das OCN's e de textos como Oliveira (2014) que se preocupam com os fundamentos epistemológicos e metodológicos do ensino de Sociologia ou mesmo o livro de Bridi, Araújo e Motim (2010) que nos oferece uma apresentação muito importante das diversas estratégias de ensino de modo muito mais aprofundado e variado do que nós podemos apresentar neste breve artigo.

\section{Considerações finais}

Se pretendemos promover uma formação humana integral no ensino médio não temos razão para negar espaço à Sociologia. Na verdade, numa formação integral os aspectos científico, tecnológico, humanístico e cultural devem estar integrados. Desta maneira, não deve haver disciplinas mais importantes e menos importantes. Sociologia e Filosofia devem contribuir para formação do aluno tanto quanto língua portuguesa e matemática.

A formação do ensino médio não deve ser exclusivamente para prestar a prova do ENEM e outros vestibulares e não deve ser exclusivamente a formação para o mercado de trabalho a partir das competências para empregabilidade. O ensino médio deve contribuir para "formação de seres humanos capazes de participar politicamente como sujeitos nas esferas pública e privada" e sua participação deve "apontar na direção de melhorias coletivas, ou seja, da construção de uma sociedade justa e melhor" (BRASIL, 2013c, p.35). Neste sentido a nossa matéria desempenha um papel muito importante no processo de escolarização que é a contribuição para o amadurecimento do estudante dado o conhecimento mais complexo do mundo social. 
Esse conhecimento mais complexo depende de um constante exercício de tomarmos as situações que fazem parte do nosso cotidiano para pensá-las de forma crítica deslocando nosso olhar para evitar a reprodução dos preconceitos, estereótipos, determinismos, apriorismos etc. A função da Sociologia, porém, não é eliminar o senso comum da cabeça dos alunos, mas de ajudá-los a lidarem com ele identificando as obscuridades, os problemas, despertando uma atitude mais investigativa, problematizadora ou crítica.

A Sociologia lida com palavras e assuntos sobre os quais os alunos já têm alguma noção, o que não quer dizer que eles tenham exatamente o mesmo significado daquele empregado no senso comum. A diferença fundamental é que tais palavras e assuntos, quando levados ao campo da Sociologia, passam sempre por uma reelaboração ou uma reconstituição o que nos ajuda a ter uma percepção mais ampla ou mais complexa daquilo que para nós é trivial, comum, normal ou natural. Portanto, não é difícil concordar com a ideia de que o objetivo da Sociologia está relacionado à desnaturalização e ao estranhamento das explicações que damos sobre o mundo. Se não fosse assim, a tarefa do professor seria de reforçar aquilo que "os leigos" já afirmam o que, por conseguinte, poderia contribuir para a manutenção de preconceitos, tornando o senso crítico desnecessário. Portanto, as aulas de Sociologia não fariam sentido.

Se a Sociologia se justifica e não deve ser retirada dos currículos em função dos objetivos a que se propõe, a falta de preocupação com a didática no seu ensino pode inviabilizar a efetivação da nossa matéria nas escolas. Daí que surge a necessidade de avançar no debate e na produção de materiais que permitam uma abordagem didática.

\section{Referências}

BRASIL, Lei No 9.394 de 20 de dezembro de 1996, que estabelece as diretrizes e bases da educação nacional. Diário Oficial da União. Seção 1 - 23/12/1996, p. 27833, Brasília-DF, 1996.

BRASIL. Orientações Curriculares Nacionais. Ministério da Educação: Brasília, 2006.

BRASIL. Ministério da Educação. Secretaria de educação básica. Sociologia: ensino médio / Coordenação Amaury César Moraes. - Brasília: Ministério da Educação, Secretaria de Educação Básica (Coleção Explorando o Ensino; v. 15), 2010.

BRASIL. Ministério da Educação. Secretaria de Educação Básica. Secretaria de Educação Continuada, Alfabetização, Diversidade e Inclusão. Secretaria de Educação 
Profissional e Tecnológica. Conselho Nacional de Educação Básica. Diretrizes Curriculares Nacionais Gerais da Educação Básica. Brasília-DF, MEC, SEB, DICEI, 2013.

BRASIL. Ministério da Educação. Instituto de Pesquisas Educacionais Anísio Teixeira. Diário Oficial da União. Edital $\mathrm{N}^{\circ} 01$ de 08 de maio de 2013. Torna pública a realização da edição do Enem 2013. Brasília-DF: INEP, 2013 b.

BRASIL. Secretaria de Educação Básica. Formação de professores do ensino médio, etapa I - caderno I: ensino médio e formação humana integral / Ministério da Educação, Secretaria de Educação Básica. Curitiba: UFPR/Setor de Educação, 2013c.

BRASIL. MINISTÉRIO DA EDUCAÇÃO. Instituto de Pesquisas Educacionais Anísio Teixeira. Edital $N^{\circ} 12$ de 08 de maio de 2014. Torna pública a realização da edição do Enem 2014. Brasília-DF: INEP, 2014.

Instituto de Pesquisas Educacionais Anísio Teixeira. Edital No06 de 15 de maio de 2015. Torna pública a realização da edição do Enem 2015. Brasília-DF: INEP, 2015 .

BRIDI, Maria Aparecida, ARAÚJO, Silvia Maria de, MOTIM, Benilde Lenzi. Ensinar e aprender Sociologia. $1^{\text {a }}$ ed. $1^{\text {a }}$ Reimpressão. São Paulo: Contexto, 2010.

CONTRERAS, José. Enseñanza, curriculum y professorado: introducción crítica a la didáctica. Madri: Akal, 1990.

DURKHEIM, Emile (1858-1917). Da divisão do trabalho social. São Paulo: Martins Fontes, 2004.

GIDDENS, Anthony. As consequências da modernidade. São Paulo: Editora UNESP, 1991.

Em defesa da Sociologia: ensaios, interpretações e tréplicas. São Paulo:

Editora UNESP, 2001.

HANDFAS, Anita; MAIÇARA, Julia Polessa; FRAGA, Alexandre (orgs.).

Conhecimento Escolar e Ensino de Sociologia. Rio de Janeiro: 7 Letras, 2015

HANDFAS, Anita e MAÇAIRA, Julia Polessa. O estado da arte da produção científica sobre o ensino de Sociologia na educação básica. BIB. São Paulo, n. 74, p.43-59, 2014.

LIBÂNEO, José Carlos. Didática. São Paulo: Editora Cortez, 2006.

MAÇAIRA, Julia; MONTEZ, Gabriela; GESTEIRA, Beatriz. Currículos em mudança: a prática do ensino de Sociologia no Rio de Janeiro. In: HANDFAS, Anita; MAIÇARA, Julia Polessa; FRAGA, Alexandre (orgs.). Conhecimento Escolar e Ensino de Sociologia. Rio de Janeiro: 7 Letras, 2015, p. 101-114.

MANNHEIM, Karl. Introdução a Sociologia da Educação. São Paulo: Cutrix, 1962. 
MARX. Karl (1818-1883). O Capital - Crítica da Economia Política. Tradução Rubens Enderle. São Paulo: Boitempo, 2013.

MILLS, C. Wright. A imaginação sociológica. Rio de Janeiro: Zahar Editores. 1965.

MORAES, Amaury Cesar e GUIMARÃES, Elisabeth da Fonseca. Metodologia de Ensino de Ciências Sociais: relendo as OCEM-Sociologia. In: BRASIL, MINISTÉRIO DA EDUCAÇÃO. Secretaria DE Educação Básica. Sociologia: ensino médio / Coordenação Amaury César Moraes. - Brasília : Ministério da Educação, Secretaria de Educação Básica (Coleção Explorando o Ensino ; v. 15), 2010.

MOTA, Kelly Cristine Corrêa da Silva. Os lugares da sociologia na formação de estudantes do ensino médio: as perspectivas de professores. Revista Brasileira de Educação, Rio de Janeiro, n. 29, p. 88-107. 2005.

OLIVEIRA, Amurabi. Os desafios teórico-metodológicos do Ensino de Sociologia no Ensino Médio. Perspectiva, Florianópolis, v. 32, n. 3, p. 1019-1044, set./dez. 2014.

OLIVEIRA, Amurabi e CIGALES, Marcelo Pinheiro. A pesquisa como princípio pedagógico no ensino de Sociologia: uma análise a partir dos livros selecionados no PNLD 2015. Ciências Sociais Unisinos. São Leopoldo, Vol. 51, n. 3, p. 279-289, setembro/dezembro 2015.

PIMENTA, Selma Garrido; et al. A construção da didática no GT Didática - análise de seus referenciais. Revista Brasileira de Educação, v. 18, n. 52, p. 143-241, janeiro/ março. 2013.

SILVA, Micheli Souza da. Grêmio Estudantil - Ensino Médio. In: SILVA, Ileizi, Luciana Fiorelli; et al. Caderno de metodologias de ensino e de pesquisa - LondrinaPR: UEL, 2009.

SOUZA, Luiz A.A. de; MANGINELLI, Francieli. Currículo escolar e ensino de Sociologia no Paraná. In: HANDFAS, Anita; MAÇAIRA, Julia Polessa; FRAGA, Alexandre (orgs.). Conhecimento Escolar e Ensino de Sociologia. Rio de Janeiro: 7 Letras, 2015, p. 308-322.

WEBER, Max (1864-1920). A ética protestante e o espírito do capitalismo. São Paulo: Companhia das Letras, 2004.

ZABALA, A. A prática educativa: como ensinar. Porto Alegre: Artmed, 1998. 